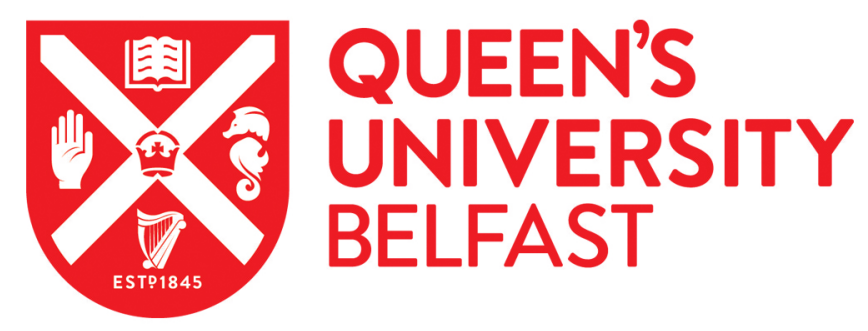

\title{
Sports coaching and the law of negligence: implications for coaching practice
}

Partington, N. (2016). Sports coaching and the law of negligence: implications for coaching practice. Sports Coaching Review. https://doi.org/10.1080/21640629.2016.1180860

\section{Published in:}

Sports Coaching Review

Document Version:

Peer reviewed version

Queen's University Belfast - Research Portal:

Link to publication record in Queen's University Belfast Research Portal

Publisher rights

(C) 2016 Informa UK Limited, trading as Taylor \& Francis Group

This is an Accepted Manuscript of an article published by Taylor \& Francis in Sports Coaching Review on 19 May 2016, available online: http://www.tandfonline.com/doi/full/10.1080/21640629.2016.1180860

\section{General rights}

Copyright for the publications made accessible via the Queen's University Belfast Research Portal is retained by the author(s) and / or other copyright owners and it is a condition of accessing these publications that users recognise and abide by the legal requirements associated with these rights.

Take down policy

The Research Portal is Queen's institutional repository that provides access to Queen's research output. Every effort has been made to ensure that content in the Research Portal does not infringe any person's rights, or applicable UK laws. If you discover content in the Research Portal that you believe breaches copyright or violates any law, please contact openaccess@qub.ac.uk. 


\title{
Sports coaching and the law of negligence: implications for coaching practice
}

\author{
Neil Partington \\ School of Law, Queen's University Belfast, UK
}

\begin{abstract}
The ordinary principles of the law of negligence are applicable in the context of sport, including claims brought against volunteer and professional coaches. Adopting the perspective of the coach, this article intends to raise awareness of the emerging intersection between the law of negligence and sports coaching, by utilising an interdisciplinary analysis designed to better safeguard and reassure coaches mindful of legal liability. Detailed scrutiny of two cases concerning alleged negligent coaching, with complementary discussion of some of the ethical dilemmas facing modern coaches, reinforces the legal duty and obligation of all coaches to adopt objectively reasonable and justifiable coaching practices when interacting with athletes. Problematically, since research suggests that some coaching practice may be underpinned by 'entrenched legitimacy' and 'uncritical inertia', it is argued that coach education and training should place a greater emphasis on developing a coach's awareness and understanding of the evolving legal context in which they discharge the duty of care incumbent upon them.
\end{abstract}

Keywords: coaching practice; negligence; reasonable; standard of care; coach education. 


\section{Sports coaching and the law of negligence: implications for coaching practice}

\section{Introduction}

It is now well established that the ordinary principles of the law of negligence are applicable in the context of sport (e.g. Caldwell v Maguire and Fitzgerald [2001] EWCA Civ 1054; Griffith-Jones, 2008), including claims brought against volunteer coaches (e.g. Petrou v Bertoncello and Others [2012] EWHC 2286; Fowles v Bedfordshire County Council [1996] ELR 51) and employed coaches (e.g. Anderson v Lyotier [2008] EWHC 2790; Cox v Dundee City Council [2014] CSOH 3). Although it may previously have been regarded as repugnant to consider suing a coach for personal injury suffered during an organised sporting activity (Adams, Adrian, \& Bayless, 1987), not least because of the traditional reliance on volunteer coaches operating in a community context (sports coach UK, 2012), this no longer appears the case (Wong, 2010). Indeed, despite the majority of personal injury claims being settled before reaching the courts in the UK (Dyson, 2013; Atiyah,1997), there is an emerging body of case law listing coaches as defendants (Partington, 2014). Unsurprisingly, coaches appear increasingly concerned about the prospects of legal liability (Greenfield, 2013; McCaskey \& Biedzynski, 1996), with most claims brought against sports coaches for sports related injuries being for negligence (Mitten, 2013). This emerging intersection between the law of negligence and sports coaching provides the focus of this article’s interdisciplinary analysis. More specifically, by problematising and critically scrutinising this issue from the perspective of the coach, through synthesis of research and case law from the different academic disciplines of law and sports coaching, interdisciplinarity (Vick, 2014) is intended to more effectively contextualise and deepen awareness of this complexity of modern sports coaching. Ultimately, it is hoped that this article might engender debate regarding the issue of the legal duty of care owed by coaches to those under their charge since this represents an important and developing issue that appears less-often highlighted in the extant literature.

Although the jurisdictional focus of this article is the UK, since the law of negligence may be regarded as generally similar everywhere (Magnus, 2006), the ensuing discussion should be of wider interest and relevance. The article begins by contextualising the issue of coach negligence since '[i]n law context is everything' (Regina (Daly) $v$ Secretary of State for the 
Home Department [2001] 2 AC 532 at [28] per Lord Steyn). This is followed by a relevant overview of the law of negligence revealing the determinative issue, should a coach be sued for personal injury suffered by an athlete under their charge, to usually centre on whether or not the coach's actions, conduct or behaviour satisfied the required standard of reasonable skill and care ordinarily expected in the same circumstances. Since this is clearly an issue of coaching practice, the article next seeks to problematise coaching practices that may be underpinned by 'entrenched legitimacy' (Cushion \& Partington 2014, p. 7), by discussing a number of ethical dilemmas facing modern sports coaches, and highlighting the dangers of negligent entrenched practice (Partington, 2014). In further developing and elaborating on some of the potential legal vulnerabilies of coaches, two cases concerning alleged negligence by coaches operating in the specific circumstances of elite sport are extensively critiqued, with detailed descriptive quotations from these judgments intended to provide a useful and constructive insight for practising coaches. Curiously, this case law analysis reveals common sense judicial reasoning, likely to be of reassurance to coaches, recognising that coaching behaviour presented by claimant athletes as intense, controlling and robust, would not necessarily amount to negligence. Next, the article affirms some important implications for coaches mindful of the emerging spectre of legal liability, including the common practice or Bolam 'defence' (Partington, 2015b).

Throughout, a central focus of this article might be regarded as defining the boundary between forging champions and committing a tort (Hurst \& Knight, 2003), or more precisely, the distinction between reasonable and negligent coaching practice. Since such a determination is highly context-specific, it is submitted that superficial reliance on codes of conduct (Hardman \& Jones, 2013; Telfer, 2010), in developing the awareness of a coach’s legal duties and obligations, seems limited. Accordingly, the article concludes by reinforcing the importance of meaningful coach education, training, and further debate and discussion regarding the emerging relationship between sports coaching and the law of negligence.

\section{Context}

As the principal supervisors of organised sporting activities, coaches must appreciate that participation in sport frequently leads to injury (Miles \& Tong, 2013). Accidents can and do happen without fault. However, in circumstances where sporting injury was caused by negligent 
coaching, legal liability may eventuate. The interpersonal relationship between coaches and athletes creates the capacity for a lack of 'empathy with or care and concern for the wellbeing of the other person' (Lyle, 1999, p. 43). Since the negligence standard is premised on reasonable care, or 'culpable carelessness' (Hartley, 2009, p. 44), the emerging interface between sports coaching and the tort of negligence is a significant complexity of modern coaching that cannot be ignored and must be addressed in an informed and proportionate manner. For instance, at the elite level, coaches are exposed to increasing demands to deliver 'cutting edge' guidance and advice to athletes (Mallett, 2010), potentially challenging the fine line between harm and reasonable endeavor when pushing the human body to its physical and emotional limits within training and performance (Telfer, 2010). Greater emphasis is now placed on coaches to regulate the volume and intensity of training loads (Miles \& Tong, 2013), this article's subsequent case law analysis revealing this to have been a material consideration before the court in Davenport $v$ Farrow [2010] EWHC 550.

More generally, some coaches may seek to gain any 'edge’ possible when conforming to the 'win at all costs' mentality frequently prevalent in a range of competitive sports (Jamieson \& Orr, 2009). This is reflective of what might be termed the 'sport ethic', with over-conformity to this ideology reinforcing the acceptance of unreasonable risks by both coaches and athletes, as evidenced by an over-emphasis on the pursuit of winning and a refusal to accept appropriate and necessary limitations (Young, 2012). Many admired and respected coaches are arguably held in such high regard because of this notable commitment and insistence on an excessive 'win-at-allcosts’ ethos (Young, 1993). Alexander, Stafford and Lewis (2011) indicate that young athletes may 'accept a culture where training through discomfort, injury and exhaustion is seen as normal' (p. 14), it being suggested that some coaches encourage athletes, or 'guilt' them, into continuing to participate in these same circumstances in order to avoid letting teammates down. Accordingly, Coakley and Pike (2014, p. 160) suggest that coaches may:

take great care to control deviant underconformity, but they often ignore or encourage overconformity, even though it may lead to injuries and have long-term negative implications for the health and well-being of athletes. Therefore, in the culture of highperformance sports, these norms are accepted uncritically, without question or qualification, and often followed without recognizing limits or thinking about the boundaries that separate normal from deviant. 
Similarly, it has been suggested that '[w]inning coaches often achieve results through techniques that could legally be considered “wanton” or "grossly negligent” in any other context' (Hurst \& Knight, 2003, p. 28). Although probably more prevalent in elite performance sport, which will provide the circumstances for this article's case law analysis, these excesses of coaching behavior may not be confined to high level competitive sport since this culture of control and authoritarianism appears deeply embedded, even at the lower levels of the sports performance pyramid (Cassidy, Jones, \& Potrac, 2009). For instance, reputation and kudos at the amateur level may facilitate adoption by coaches of high-risk practices with the potential to cause physical harm (Young, 2004), it being assumed that some coaches at the non-professional level appear unsympathetic to athletes complaining of being injured (Pike \& Scott, 2015; Young \& White, 1999). At the elite level, there is also evidence to indicate that soccer coaching behaviours can often be belligerent, reflective of the culture in professional soccer, preparation for the rigours of the game regarded as requiring young players to be exposed to harsh and authoritarian approaches to coaching (Cushion \& Jones, 2006; Williams \& Hodges, 2005). In short, contextualisation of modern sports coaching clearly illustrates the scope for potential legal vulnerability, or 'culpable carelessness', and more specifically, the need for all coaches to have regard to the somewhat elusive and nebulous boundary between optimising performance or acting negligently. Importantly, should courts be tasked with defining this distinction, application of ordinary principles from the law of negligence would usually expose the coaching practices adopted to robust and searching judicial scrutiny.

\section{Law of Negligence}

A sports coach may be found legally liable in negligence in the UK where it can be established by the claimant (athlete) that the defendant (coach): (i) owed the athlete a duty of care (duty); (ii) that this duty of care was breached (breach/fault); and, (iii) the breach in question caused foreseeable personal injury to the athlete (causation). Since the tort of negligence is underpinned by the 'neighbour principle’ (Donoghue v Stevenson [1932] AC 562), requiring the exercise of reasonable care to avoid injuring anyone who ought reasonably to be considered as being affected by one's actions or omissions, it is immediately apparent that coaches must display reasonable care when assuming such a role (Beloff et al., 2012; Griffith- 
Jones, 2008; James, 2013). Given the supervisory, instructional and safety functions of a coach, arguably providing the foundation of the coach-athlete relationship, it is just, fair and reasonable (Caparo v Dickman [1990] 2 AC 605), and indeed well-settled law, that coaches owe a duty of care to athletes (e.g., Fowles v Bedfordshire County Council [1996] ELR 51; Anderson v Lyotier [2008] EWHC 2790; Morrow v Dungannon and South Tyrone Borough Council [2012] NIQB 50). Accordingly, the law of negligence's control mechanism of duty, in the context of sports coaching, would tend to be straightforwardly satisfied by athlete claimants.

Before turning to the usually determinative issue of breach of duty, the second of the aforementioned control devices typically posing little difficulty to establish for claimants would appear to be causation. Since establishing both causation in fact (Barnett $v$ Chelsea and Kensington Hospital Management Committee [1969] 1 QB 428), and legal causation (Overseas Tankship v Morts Docks \& Engineering Co Ltd (The Wagon Mound No. 1) [1961] AC 388) is generally unambiguous for participant liability (James, 2013), in the main, it is contended that causation inquiries for cases of alleged coach negligence should also tend normally to be uncomplicated (e.g., Cox v Dundee City Council [2014] CSOH 3, Woodroffe-Hedley v Cuthbertson, Unreported, 20 June 1997). Consequently, proceeding on the premise that firstly, a sports coach owes a duty of care to those under their charge, and secondly, that establishing causation would typically not appear problematic in this context, should a claim be brought against a sports coach for alleged negligence, the decisive factor would most probably be whether the coach fulfilled the duty to exercise reasonable care for the protection of the performer (Labuschagne \& Skea, 1999). Simply applied, the pivotal issue in coach negligence cases concerns the standard of skill and care incumbent on the defendant coach (Partington, 2014, 2015b; Kevan, 2005), or the tort of negligence's control mechanism of breach, this being informed and moulded by the full factual context and circumstances in which the defendant sports coach was operating (Griffith-Jones, 2007; James, 2013).

More precisely, a finding of liability in negligence would involve establishing that the sports coach's conduct had fallen below the required objective standard ascertained by the court (Nettleship v Weston [1971[ 2 QB 691), in guarding against reasonably foreseeable risk (Overseas Tankship (UK) Ltd v The Miller Steamship Co (The Wagon Mound No. 2) [1967] 1 
AC 617), in the specific circumstances (e.g., Bolton $v$ Stone [1951] AC 850; section 1 of the Compensation Act 2006; Social Action, Responsibility and Heroism Act 2015; see, further, Partington, 2015a). This benchmark of objective reasonableness is defined to safeguard the legitimate and genuine right of athletes not to be exposed to unreasonable risks, but crucially, providing coaches discharge and meet this standard of skill and care, there can be no liability in negligence. However, since coaching practice is complex and highly situation-dependent, the distinction between reasonable and negligent coaching conduct remains somewhat elusive and imprecise (Hardman \& Jones, 2011; Partington, 2014). This is compounded by the essentially vague and woolly nature of reasonableness as a legal test which fails to provide much by way of guidance when attempts are made to define the standard of care (Clancy, 1995). Since this benchmark is strikingly fact sensitive (Norris, 2009), although judicial clarification of the level of due care necessary to avoid breaching the duty of care owed to athletes would be advantageous by providing a transparent illustration for coaches (Fulbrook, 2005), this seems improbable. This reinforces the importance of coach education provision developing coaches' 'socially informed decision-making skills' (Jones, 2000, p. 34), as this might more effectively encourage and support coaches in unpacking and clarifying 'reasonableness' in the varying and specific contexts in which they function.

Crucially, any practice requiring special skill, knowledge or experience, including the coaching of sport (Fowles v Bedfordshire County Council [1996] ELR 51; Davenport v Farrow [2010] EWHC 550), requires a higher standard of care to be displayed than would be expected of the ordinary reasonable person (Lunney \& Oliphant, 2013; Jones \& Dugdale, 2010). Put simply, the standard of skill and care exercised by coaches should be consistent with that expected of the ordinarily competent coach in the same circumstances. Interestingly, in being mindful of the wider professionalisation of sports coaching agenda, this legal test recognises the enhanced difficulty and skill in the working practices of professionals (Mangan, 2014), with the imposition of this legal obligation or duty of care often regarded as 'a badge of professional status’ (D v East Berkshire Community Health Authority [2005] 2 AC 373 at [40] per Lord Bingham). Nonetheless, these same legal principles would also appear to be applicable to individuals not regarded as being members of a profession but whose functions demand the exercise of a special skill (Lunney \& Oliphant, 2013). Further, whether or not the coach may 
have some formal recognition of their specialisation would appear immaterial (Powell and Stewart, 2012), as would classification as amateur or professional (Gardiner, 1993), the standard required remaining appropriate to specialists operating at the same level in that designated field. Somewhat paradoxically, given the predominant reliance on volunteer coaches in the UK, this means that on occasions courts would appear to be tasked with essentially determining what might be termed the 'professional liability of amateurs' (Partington, 2015b \& 2016).

Moreover, this would not appear to be a static legal test, since as the principles of coaching are constantly assessed and revised (Trudel, Gilbert \& Werthner, 2010; Cassidy et al., 2009; Taylor \& Garratt, 2010), so too is the likely legal standard of care required of coaches (Powell \& Stewart, 2012). Further, as performers progress to elite and excellence levels the required emphasis on more specialised training programmes creates new risks requiring coaches to ensure that they possess the necessary competence and expertise to operate safely in these amended circumstances (Labuschagne \& Skea, 1999). This acknowledges the importance of continuing 'professional' development, coach education and training for all coaches.

Correspondingly, coaches have an obligation to ensure that their level of competence (i.e., qualifications, training and/or experience) is commensurate to the performance level at which they are coaching, since any possible skills gap (see, for instance, Lynn \& Lyle, 2010; Lyle \& Cushion, 2010) may expose athletes to unreasonable risk, thereby heightening the coach's exposure to legal liability in negligence.

In seeking to raise awareness and facilitate debate concerning some of the implications for coaches derived from the interaction between the law of negligence and sports coaching, this article next seeks to problematise this issue and highlight a number of ethical dilemmas facing modern sports coaches. This should prove both instructive and insightful since fulfilment of the legal duty of discharging reasonable care may be regarded as consistent with the ethical obligation not to expose athletes to unreasonable risks of injury (Mitten, 2013). For instance, an important relevant dilemma, which is subsequently exposed to fuller analysis by scrutinising related case law from the context of elite sport (Brady v Sunderland Association Football Club Limited and Others (Unreported, 2 April, 1998 Queen’s Bench Division); Davenport v Farrow [2010] EWHC 550), concerns decisions by coaches on 'how hard to "push"” athletes in order to 
optimise performance and gain a competitive 'edge'. This often fine line appears particularly acute when coaches might perceive a lack of commitment, or 'attitude problem', on behalf of the athlete(s) being coached. As the following case law analysis reveals, viewed from the contrasting perspective of the athlete, intense and demanding coaching behaviour may sometimes be regarded as too authoritarian, inappropriate, oppressive and controlling. Since the legal requirement is for coaching practice to be objectively reasonable, both the perspective of the coach and injured athlete, supported by additional relevant evidence, including complementary expert witness testimony, would likely inform the court's deliberations when tasked with determining the boundary between reasonable or negligent coaching.

\section{Coaching Practice}

The pivotal issue should a coach be sued in negligence concerns whether or not the coach's actions, conduct or behaviour satisfied the required standard of reasonable skill and care, as defined by the court, after taking full account of the unique circumstances of the case. This obligation encompasses both acts and omissions (ie., negligent instruction and inadequate supervision). In the context of sports coaching, this would appear to relate to coaching practices that have an explicit impact on the athlete, most typically, direct coaching interventions and interactions in the particular circumstances of training, practices, competitions and fixtures. Simply applied, coaches have a legal responsibility to ensure that the coaching practices adopted and employed are reasonable.

Much contemporary coaching practice appears to be underpinned by emulation, intuition and tradition, or 'uncritical inertia' (Partington \& Cushion, 2013; Williams \& Hodges, 2005; Ehrmann, 2011). This may 'authenticate certain types of collective knowledge with the resulting discourse giving certain practices an entrenched legitimacy' (Cushion \& Partington 2014, p. 7). Problematically, in circumstances where this entrenched legitimacy exposes athletes to unreasonable risk of injury, coaches may inadvertently be exposed to liability in negligence as a result of negligent entrenched practice (Partington, 2014). For instance, it is comprehensible that coaches working in the context of elite sport, seeking to optimise the performance levels of the athletes by repeatedly pushing players to the limit of their physical and mental performance 
thresholds, may be reluctant to take extra (reasonable) precautions in practice (Lines, 2007). This feasible scenario illustrates the need for coaches to have the prerequisite self-awareness to understand both the positive and negative implications of their behavior (Cushion, 2010). Nonetheless, since research indicates that coaches may demonstrate low self-awareness about their coaching practice and behaviour (Partington \& Cushion, 2013; Harvey, Cushion, Cope \& Muir, 2013; Cushion, 2010), the reasonableness of demands made of athletes by coaches may not always be sufficiently appraised, evaluated and reflected upon. The fact coaching practitioners often operate in isolation (Trudel, Gilbert \& Werthner, 2010), likely restricting opportunities for critically constructive and informed discussion, and the sharing of best practice, probably compounds the capacity for negligent entrenched coaching methods to be incorporated into coaching practice unwittingly and without question.

Arguably, authoritative and oppressive interaction between coaches and players, and possible implementation of punishment type drills and practices, may become regarded as routine and acceptable in certain circumstances (Kellett, 2002; Ehrmann, 2011). Take for example, some of the conditioning/punishment type drills modelled and reinforced, and portrayed as necessary and effective coaching practice, in contemporary films including Coach Carter, Remember the Titans and Best Shot. This includes a high intensity shuttle-sprint training drill, commonly referred to as 'suicides'. While many coaches will, no doubt, utilise such methods reasonably, as this article’s legal analysis reveals, coaches must be cautious when using exercise drills as a form of punishment (Wong, 2010). In fact, consideration of this particular coaching practice through this article's interdisciplinary lens, and being mindful of better safeguarding coaches from litigation risk, appears to problematise the label 'suicide' drill. In advocating the avoidance of such terminology by coaches, Appenzeller (2011) notes that this and similar such terms ‘could come back to haunt you in court should an injury occur’ (p. 153). Put bluntly, it may be particularly challenging for coaches engaging in such coaching methods as a matter of habit, routine, or uncritical inertia, to justify such practice as being objectively reasonable. This is submitted to be a possible scenario where there would appear to be the potential for possible negligent entrenched practice to be 'accepted uncritically, without question or qualification, and often followed without recognizing limits or thinking about the boundaries that separate normal from deviant’ (Coakley \& Pike, 2014, p. 160). 
A significant ethical dilemma facing modern sports coaches, not least when working with young athletes, concerns determination of training intensity levels (see, for instance, Miles \& Tong, 2013; Lyle, 2002). As will be highlighted in the later case law analysis, insightful and instructive judicial comments on this important issue were made by Mr Justice Owen in Davenport v Farrow [2010] EWHC 550. For present purposes, it is important to note that this is generally a judgment call left to the discretion of individual coaches based on the specific circumstances. In short, this is an area where coaches have to be trusted to make the right (or reasonable) decisions (Cassidy et al 2009).

According to Martínková \& Parry (2011, p. 177-78):

The dangers of over-training and inappropriate methods have long been recognized, as have the duties of the coach to be knowledgeable and well informed, to take care over the appropriate design of training session schedules, and to monitor athletes for signs of weariness and distress.

In terms of effective coaching practice, Cross \& Lyle (1999, p.192) continue:

coaches have a responsibility to implement a coaching process, especially with elite and high-level performance athletes, which is comprehensively planned, adequately and frequently monitored and in which, through careful regulation of the training loading factors, the athlete's progress and wellbeing are constantly emphasised in order to avoid 'overtraining'.

Yet, despite the long recognition of the risks posed to athletes by overtraining and inappropriate training methods and practices, research would suggest that excessive training, both in terms of the intensity and duration of sessions, remains a concern (Alexander, Stafford \& Lewis, 2011).

More positively, in view of the dynamic environment in which coaches operate, the law recognises that there may be a number of perfectly proper standards or practices (Bolam $v$ Friern Hospital Management Committee [1957] 1 WLR 582; Montrose, 1958), providing the coaching decisions made were 'within a reasonable range of options' (Woodbridge School v Chittock [2002] EWCA Civ 915; Davenport v Farrow [2010] EWHC 550 at [59]). Since sports coaching 'consists of a continua of highly complex, context-dependent and historically situated behaviours’ (Hardman \& Jones, 2011, p. 78), courts tasked with determining a coach negligence case would be able to recognise that no 'transparent, fixed and universally accepted boundary 
[exisits] between appropriate and inappropriate coaching conduct' (Hardman \& Jones, 2011, p. 78). Consistent with the previously highlighted uncertainty generated from a test premised on reasonableness, this would, therefore, seem to advocate the relevance and necessity for further discussion of ethical dilemmas drawn from practical coaching scenarios in order to support coaches in developing reasonable and effective coaching practices (see, generally, Cassidy et al 2009).

The following detailed analysis of two cases, from the context of elite sport, provides an important and interesting insight regarding judicial scrutiny of the coaching practices and behaviours adopted in the particular circumstances should a coach be sued for alleged negligence.

\section{Case law analysis}

\section{Brady v Sunderland Association Football Club Limited and Others (Unreported, 2 April, 1998 Queen's Bench Division)}

\section{Facts}

The claimant/plaintiff, was a highly promising young footballer, having played for the Sunderland First Team and the Republic of Ireland Under-21 and Youth Teams. Due to a likely vascular problem in his right leg, and despite several operations, he was unable to pursue his career as a professional footballer. For present purposes, the action brought by the claimant essentially amounted to an allegation that the club had breached its duty of care owed to him by failing to properly heed or investigate obvious physical problems and/or complaints, with a subsequent failure to refer him to a doctor. It was alleged on behalf of the claimant that complaints by the player, and apparent difficulties in training, were attributed to an attitude problem and that any referral to a doctor would have led to a diagnosis of possible vascular problems which would have been investigated at a time when treatment would have been successful. Though ultimately unsuccessful, despite the case also being heard by the Court of Appeal, detailed examination of the judgment from the perspective of a coach provides an important insight regarding the likely scrutiny by courts of the conduct of coaches should a coach be sued in negligence. 


\section{Analysis}

The duty of a coach is to exercise reasonable skill and care to ensure that those under the coach’s charge are not exposed to unreasonable or unacceptable risk in the particular circumstances. Although the standard expected of sports coaches is fixed conceptually as the duty to take reasonable care, specific duties required of coaches have evolved (McCaskey \& Biedzynski, 1996), with Barnes (1996) suggesting that coaches are required to discharge responsibilities that may be classified under three main headings which include: facilities and organisation; instruction and supervision; and medical care (see, further, Anderson, 2010; Beloff et al., 2012; Cox \& Schuster, 2004). According to Martens (2004), the medical responsibilities of a coach include making sure that the athlete's health is satisfactory prior to participation; determining when an athlete's illness or injury should prevent further participation; and, only permitting athletes to return to active participation when it is safe to do so. Significantly, in Brady v Sunderland Association Football Club, when assessing the reasonableness of the Club's actions, and more specifically, the behaviour of the manager/coach, these were material considerations for the court. Subsequently, given the particular facts of this case, the reasonableness of the instruction, supervision and referral to the club’s physiotherapist for medical attention, by the coach/manger, was a pivotal matter in determining the outcome of the trial. As succinctly put by the judge, Mr Justice Buckley:

the real issues are whether the plaintiff complained of, as opposed to experienced, symptoms which should have led to an earlier referral to [the Club's honorary Doctor] or whether the Club, through [the Club's physiotherapist] or the manager ... should otherwise have spotted them and made such a referral.

In prioritising the perspective of the manager/coach, and consistent with this article's objectives of providing a detailed insight, and greater awareness, of the scope for civil liability, interesting aspects of the claimant's submissions when seeking to make out the allegation of negligence included:

- During a training run, after complaining of severe pain in his calf to the manager, the claimant was told to keep running with the other players, the manager/coach saying he didn't care what the claimant had and that he could see the physiotherapist after training. 
- The coach was repeatedly telling the claimant that he had an attitude problem, particularly in relation to training.

- When referring to a six mile run completed at a later date, in his witness statement, the claimant stated that the manager 'told me that he wasn't going to put up with any more nonsense. He told me that I couldn't stop and to keep going. He then sent the other players off in a different direction and he ran with me along the coast lecturing me about my attitude and telling me I just didn't like hard work. At the end of the run he told me I could go to see the physiotherapist'.

While finding the claimant to be an honest witness, the court acknowledged the difficulty faced by him in recalling details from almost six years prior to the hearing of the case. Further, the transient nature of the claimant's injury, combined with the admission that he did not like training without the ball, persuaded Buckley $\mathrm{J}$ that it had been understandable and reasonable for the manager to conclude that the claimant had an attitude problem. On this issue, the High Court's judgment concludes,

[The manager/coach] agreed he did not like the plaintiff's attitude at times. He said he was a talented player, but one who needed to work harder. He was fine with the ball but not without it was how he described him. He felt the plaintiff did not work hard at stamina running or with weights and had a poor attitude to hard training generally. There is a measure of common ground here because the plaintiff was conscious that [the manager/coach] felt he had an attitude problem and he accepted he didn't like stamina training and preferred training with the ball. He was disenchanted with the coaching staff.

Crucially, the judgment of Buckley $\mathrm{J}$ at first instance, quite correctly, makes plain that, '[e]ven if [the manager's] attitude at the time was robust - and it probably was - in all the circumstances, that does not begin to amount to negligence'. Employing this article's scrutiny of appropriate coaching practice, the autocratic and authoritarian coaching style, perhaps prevalent within the culture in professional soccer (Cushion \& Jones, 2006), and allegedly adopted by this manager/coach, was regarded by the court to have been reasonable in the circumstances of professional football at that time. Ultimately, the claims of a breach of duty of care by the Club, and its agents (including the manager/coach and physiotherapist), failed. Nonetheless, reflecting more widely on Brady v Sunderland Association Football Club, although not established on the particular facts of this individual case, it becomes clear that causes of action that may be brought against coaches might be founded on: negligent supervision and/or instruction; ineffective provision of medical care/referral; pressuring injured players to perform; and, failure to ensure 
that the intensity of training sessions and practices is within reasonable parameters of acceptable coaching.

The recent case of Davenport v Farrow provides a further, and fuller, detailed illustration and unpacking of these specific duties owed by coaches to athletes under their charge.

\section{Davenport v Farrow [2010] EWHC 550}

\section{Facts}

The defendant coach in this case was extremely successful, holding the highest level of formal qualification accredited by UK Athletics. The claimant was an athlete of world class potential, having broken the UK Junior record for the 400 metre hurdles at the World Junior Championships in 2004. The claimant's case, somewhat consistent with that argued by counsel in Brady v Sunderland Association Football Club, alleged that he sustained stress fractures in October/November 2004, causing significant pain which affected his ability to train, and which he drew to the attention of his coach. However, it was contended by the athlete that his coach ignored these complaints, dismissing them as symptomatic of a lack of motivation on the part of the claimant. Subsequently, it was submitted that in breach of his duties to the claimant, whether contractual or tortious, the defendant coach failed to take the complaints seriously, assuring the claimant that there was nothing wrong with him. It was further asserted that the coach ought to have advised the claimant to have the condition investigated, and that had an investigation then taken place, the stress fractures would have been treated conservatively with rest, and that, on the balance of probabilities, they would have united satisfactorily without surgical intervention. In short, the court was of the view that the claimant's case depended upon when the stress fractures occurred, since if the fractures pre-dated October/November 2004, then there could be no causal relationship between the alleged failure on the part of the defendant coach to respond to the claimant's complaints of back pain during the relevant period, and the injury, loss and damage for which the claimant contended. Consistent with the theme of this article, it is the scrutiny of the coach's conduct by the court, in light of admissions by the claimant, which will provide the main focus of the following analysis. 


\section{Analysis}

Importantly, both sides in this case called other athletes trained by the defendant coach to provide evidence. One such athlete, 'EP', recalled how the defendant 'was continually on about the fact that [the claimant] was lazy and that there was nothing wrong with him' (Davenport $v$ Farrow [2010] EWHC 550 at [23] per Owen J). Crucially, in highlighting the potential significance of the specific circumstances of the case, including the coaching style adopted by defendant coach, Owen J recognised:

There is a further aspect of the evidence that bears on the issue. The claimant contends that the defendant was a forceful and controlling personality who demanded a high level of control over young athletes whom he coached. He gave evidence that the defendant wanted a say in all aspects of his life. The defendant would telephone on an almost daily basis, and would question his mother about what she was feeding him, wanting to control his diet (at [27]).

This evidence regarding the authoritarian practice employed by the defendant coach was further supported by the evidence of 'EP', who elaborated:

Looking back at my time with [the defendant coach], I had not realized how controlling [he] was over his athletes. With hindsight, he was incredibly controlling. He controlled everything. [He] told me what I could eat, he insisted that I weigh my food so I just got enough. He said that if I went to bed hungry then I would burn more fat whilst I slept and keep my weight down (at [28]).

Arguably, a more objective assessment of the defendant's approach to coaching, or coaching practice, was provided during the court hearing by the then Director of Coaching for Track and Field Events at Loughborough University:

Knowing [the coach], he is pretty steadfast in his views on how someone should be coached and is not someone who readily listens to someone else's views. He is also controlling in the way in which he handles his athletes and he dictates how things are done. Younger athletes will tend to accept what their coach tells them in terms of how they train and what treatment they need and I can understand when [the claimant] says he accepted [his coach’s] advice on things (at [30]).

Cases brought in negligence are always highly fact sensitive (Norris, 2010) and dependent upon the particular circumstances of each individual case. Interestingly, in another sports negligence case, Caldwell v Maguire, Judge LJ reiterated in the Court of Appeal that 'the 
issue of negligence cannot be resolved in a vacuum. It is fact specific' (Caldwell v. Maguire and Fitzgerald [2001] EWCA Civ. 1054 at [30]). Accordingly, in Davenport v Farrow, the defendant coach's relationship with the athletes that he trained, and more specifically, the coach's behaviour and practice, contextualised for the court assessment of the claimant's submissions in relation to his back pain. A further corresponding matter relating to both Davenport v Farrow, and Brady v Sunderland Association Football Club, and likely to be of some relevance in future cases, concerns what coaches frequently term an 'attitude problem' of the athlete(s) being coached. On this, the judgment of the court in Davenport v Farrow found:

Secondly the evidence as to the nature of their relationship is relevant in that the claimant contends that it provides an explanation as to why his complaints were ignored by the defendant. The evidence shows clearly that from December 2004 until they parted company, the defendant considered that the claimant lacked motivation and had an attitude problem (at [32]).

Owen J continued,

The claimant gave evidence that he thought that the defendant believed that the problem that he was reporting with his back was just an attempt to get out of training. ['EP'] recalled the defendant saying continually at this time that the claimant was lazy and that there was nothing wrong with him. ['LP', another athlete] gave evidence that if you were someone who was lazy and lacked credibility, then any aches and pains would be met by the defendant with some cynicism (at [35]).

While it may be reasonable for coaches, on occasions, to become frustrated with athletes due to a lack of commitment, hard work and intensity, the court's attention concentrates on how an ordinarily reasonable coach in the same circumstances would behave. Crucially, this is an objective test of reasonableness which would not reflect the subjective idiosyncratic personal tendencies, for instance, possible excessive cynicism, of individual coaches. Simply applied, the negligence standard demands that defining the boundary between what might amount to appropriate coaching behaviour, as opposed to pushing athletes too hard, is a question of what is objectively reasonable, and justifiable, in the same circumstances. Consequently, a further contemporaneous source of information considered by the court in Davenport v Farrow, and likely to be instructive and informative for all coaches, was a screening report, compiled as part of a programme of regular screening, due to the fact that the claimant had been enlisted in the 
UK Athletics programme for athletes with world class potential. This 'SW Potential athlete report' contained the following statement on the claimant:

From discussion with [the defendant coach] and feedback from Darcy appears training programme is all in place. However, concerns over controlling nature of relationship between coach and athletes ... and strong possibility that athletes are being pushed too hard too early. Prevalence of injuries in whole group suggests this may be case (at [41]).

Significantly, critical scrutiny of the judicial reasoning from both of these cases, and consideration of the material facts presented to the court, reinforces the necessity for coaching practice to be reasonable and commensurate to the specific circumstances in which the athlete is performing. This reinforces the good practice of coaches critically reflecting upon the suitability and appropriateness of their coaching behaviours, thereby ensuring that the coaching methods employed are rigorously justifiable. In this regard, should a coach be sued, the court would likely be able to peruse expert witness testimony when seeking to define what might amount to reasonable coaching practice in the same circumstances. For instance, in ultimately dismissing the claim against the defendant coach, the High Court concluded:

[the claimant's] case was advanced upon the basis that the probable cause of an acute spondyloyses was a marked increase in the intensity of his training from September 2004. There was an increase in the number of sessions as the Claimant had begun training on a full time basis; but I accept the evidence of the Defendant, given by reference to his training programmes for the Claimant, that it was a moderate increase from the same period in the previous year, and was not therefore significantly more than he had done in the past. It is also to be noted that in this context that in their joint statement, the coaching experts whose reports were before the court, agreed that the regime undertaken in 20042005, based on the Defendant's training log, was within the range of acceptable coaching (level 4) for an athlete of his ability and aspirations. I am not persuaded that there was a change in the level and intensity of training in September 2004 such as to provide an explanation for the development of spondyloyses (at [59] per Owen J).

\section{Some implications}

The above interdisciplinary analysis of both Brady v Sunderland Association Football Club, and Davenport v Farrow, confirms that overtraining, or training requiring an unreasonable level of intensity, may provide the foundation for a cause of action in negligence. Further, coaches must be mindful to avoid exerting undue pressure or influence on players returning from 
injury, in addition to discharging responsibilities regarding appropriate medical care of athletes, including pertinent referral to relevant specialist medical practitioners and adherence to stipulated protocols. Also, the searching inquiries conducted by the court reinforces the need for coaches to keep written records of such things as training sessions delivered, schedules of training programmes, attendance registers, injuries sustained by participants, performance and fitness assessments (Barnes, 1996; Whitlam, 2012); and all other relevant information, for instance risk assessments (Uren v Corporate Leisure (UK) Ltd Ministry of Defence [2011] EWCA Civ 66) and, depending on the level at which the coach is operating, medical screening test results and records of progression reviews/meetings (i.e., Davenport v Farrow).

More generally, as alluded to in the joint statement by the expert witnesses in Davenport v Farrow: (i) regular and approved coaching practices (i.e., advocated by a responsible coaching organisation/NGB; Bolam v Friern Hospital Management Committee [1957] 1 WLR 582); that are (ii) logically justifiable (Bolitho v City of Hackney Health Authority [1998] AC 232); and, (iii) suitable for the post or position of the coach (i.e., appropriate to the performance level in question; Wilsher v Essex Area Health Authority [1987] QB 730), are hallmarks of reasonable coaching practice (Partington, 2014, 2015b). When critically evaluating and reflecting upon their coaching practice, successfully satisfying these three legal propositions should safeguard coaches from negligence liability by means of a common practice or Bolam 'defence' (Partington, 2015b). In short, coaches with the developed self-awareness to continuously evaluate the appropriateness of their coaching practice, and thereby successfully satisfy these propositions which are indicative of reasonable coaching, in addition to better protecting the safety and welfare of athletes, would be more likely to be shielded from negligence liability.

\section{Codes of Conduct}

In attempting to address many of the ethical (and legal) dilemmas encountered by coaches, there would appear to be an unexamined and superficial reliance by coaching organisations on codes of conduct (Hardman \& Jones, 2013). Since the assumption seems to be that ethical considerations regarding coaching practice will be understood and grasped intuitively by coaches (Telfer, 2010), the extent to which codes of conduct impact and shape coaching behaviour appears open to conjecture and debate (Taylor \& Garratt, 2010; Cassidy, 2013). With 
specific regard to the emerging interface between the law of negligence and sports coaching, this represents a significant missed opportunity given the qualified overlap between legal and ethical obligations (Mitten, 2013). Put simply, the utility and beneficial impact of codes of conduct for coaches, in developing the awareness of legal duties and obligations, seems limited.

Correspondingly, although informal or unofficial CPD can be advantageous as a means of coach development, it may conversely reinforce poor practice (Armour, 2010), or more precisely, negligent entrenched practice. Significantly, Duffy et al. (2011) have recognised the importance of the need for the legal and ethical aspects of sports coaching to become more enhanced topics within the CPD provision of coaches, with evidence to indicate a demand from coaches for more training on health and safety issues, including risk management and (ir)responsible coaching (Stirling, Kerr \& Cruz, 2012). This article's critical scrutiny of the implications for coaching practice of the interaction between sports coaching and the law of negligence endorses this view.

\section{Conclusion}

All coaches, regardless of their classification as amateur or professional, should have an informed awareness of the emerging relationship between sports coaching and the law of negligence. This article's interdisciplinary analysis of the legal liability of coaches, through a lens intended to better safeguard coaches from litigation risk, reinforces the responsibility of coaches to adopt objectively reasonable and justifiable coaching practices when interacting with athletes. Although at first glance, this may appear to be a trite observation, this article has problematised coaching practice that may be informed by entrenched legitimacy, and 'uncritical inertia', by discussing a number of ethical dilemmas facing modern sports coaches. Detailed scrutiny of two relevant court judgments further developed, unpacked and clarified this theme. Unexamined and superficial reliance on coaching codes of conduct fails to appropriately account for this developing and highly context-specific complexity of contemporary coaching. Clearly, there is a requirement for NGBs and coaching associations to proactively support and develop coaches to ensure that they are appropriately protected from the evolving risk of liability in negligence (Partington, 2014). Since an aim of relevant and engaging coach education courses should be to assist coaches in constructing (context-specific) knowledge, rather than merely receiving it (Nash, 2015), it is contended that discussion of relevant case law examples, for instance, Brady v Sunderland Association Football Club and Davenport v Farrow, would 
provide coaches with instructive scenarios designed to stimulate critical reflection of legal and ethical issues. In transcending some of the present limitations of codes of conduct, this should more effectively guide coaches in establishing an awareness and understanding of the dynamic legal context in which they discharge the duties incumbent upon them. Further, since the guidelines provided by codes of conduct informs the 'professional' behaviour of coaches (Telfer, 2010), fuller engagement with this issue may inform the professionalisation of sports coaching agenda. More specifically, it is hoped that this article might engender further debate concerning the legal duties and obligations of coaches. In addition to emphasising the safety and welfare of athletes, should the unfortunate need arise, this would correspondingly enable the coach's acts or omissions to be more capable of withstanding robust and searching judicial scrutiny.

\section{Acknowledgements}

The author would like to thank Prof. Jack Anderson and Dr. David Capper for their informative comments on an earlier draft of this article. 


\section{References}

Adams, S., Adrian, M., \& Bayless, M. (Eds.). (1987). Catastrophic Injuries in Sport; Avoidance Strategies. Indianapolis, IN: Benchmark.

Alexander, K., Stafford, A., \& Lewis, R. (2011). The experiences of children participating in organised sport in the UK. Edinburgh: University of Edinburgh/NSPCC Child Protection Research Centre.

Anderson, J. (2010). Modern Sports Law: A Textbook. Oxford: Hart.

Appenzeller, H. (2011). Ethical Behavior in Sport. Durham, NC: Carolina Academic Press.

Armour, K. (2010). The learning coach ... the learning approach: Professional development for sports coach professionals’. In J. Lyle \& C. Cushion (Eds.), Sports coaching: Professionalisation and practice (pp. 153-164). Edinburgh: Churchill Livingstone Elsevier.

Atiyah, P. (1997). The damages lottery. Oxford: Hart.

Barnes, J. (1996). Sports and the Law in Canada. London: Butterworths.

Beloff, M., Kerr, T., Demetriou, M., \& Beloff, R. (2012). Sports law. Oxford: Hart.

Cassidy, T. (2013). Exploring ethics: Reflections of a university coach educator. In S. Harvey \& R. L. Light (Eds.), Ethics in youth sport: Policy and pedagogical applications (pp. 149-169).

London: Routledge.

Cassidy, T., Jones, R., \& Potrac, P. (2009). Understanding Sports Coaching: The Social, Cultural and Pedagogical Foundations of Coaching Practice. London; Routledge.

Clancy, R. (1995). Judo mats, climbing walls, trampolines and pole vaulters. Sport and the Law Journal, 3, 28-31.

Coakley, J., \& Pike, E. (2014). Sports in Society: Issues and Controversies. Berkshire: McGrawHill Education.

Cox, N., \& Schuster, A. (2004). Sport and the law. Dublin: First Law.

Cross, N., \& Lyle, J. (1999). Overtraining and the coaching process. In N. Cross \& J. Lyle (Eds.), The Coaching Process: principles and practice for sport (pp. 192-209). Oxford: Butterworth-Heinemann.

Cushion, C. (2010). Coach behaviour. In J. Lyle \& C. Cushion (Eds.), Sports coaching: professionalisation and practice (pp. 43-62). Edinburgh: Churchill Livingstone Elsevier. 
Cushion, C., \& Jones, R. (2009). Power, Discourse, and Symbolic Violence in Professional Youth Soccer: The Case of Albion Football Club. Sociology of Sport Journal 23, 142-161.

Cushion, C., \& Partington, M. (2014). A critical analysis of the conceptualisation of 'coaching philosophy’. Sport, Education and Society, DOI: 10.1080/13573322.2014.958817.

Duffy, P., Hartley, H., Bales, J., Crespo, M., Dick, F., Verdhan, D., Nordmann, L., \& Curado, J. (2011). Sport coaching as a 'profession': challenges and future directions. International Journal of Coaching Science, 5(2), 93-123.

Dyson, Lord, Master of the Rolls. (2013). Compensation Culture: Fact or Fantasy? Holdsworth Club Lecture.

Ehrmann, J. (2011). Insideout coaching. New York, NY: Simon \& Schuster.

Fulbrook, J. (2005). Outdoor activities, negligence and the law. Aldershot: Ashgate.

Gardiner, J. (1993). Should coaches take care? New Law Journal, 143, 1598.

Greenfield, S. (2013). Law's impact on youth sport: should coaches be 'concerned about litigation'? Sports Coaching Review, 2(2), 114-123.

Griffith-Jones, D. (2007). Law and the business of sport. Haywards Heath: Tottel.

Griffith-Jones, D. (2008). Civil Liability Arising Out of Participation in Sport. In A Lewis \& J Taylor, Sport: Law and Practice (pp. 711-752). Haywards Heath: Tottel.

Hardman, A.R., \& Jones, C. (2010). The Ethics of Sports Coaching. London: Routledge.

Hardman, A., \& Jones, C. (2013). Philosophy for coaches. In R. L. Jones \& K. Kingston (Eds.), An introduction to sports coaching: Connecting theory to practice (pp. 99-111). London: Routledge.

Hartley, H. (2009). Sport, Physical Recreation and the Law. London: Routledge.

Harvey, S., Cushion, C., Cope, E., \& Muir, B. (2013). A season long investigation into coaching behaviours as a function of practice state: the case of three collegiate coaches. Sports Coaching Review, 2(1), 13-32.

Hurst, T., \& Knight, J. (2003). Coaches’ liability for athletes’ injuries and deaths. Seton Hall Journal of Sports Law, 13, 27-51.

Martínková, I., \& Parry, J. (2011). Coaching and the ethics of performance enhancement. In A. R. Hardman \& C. Jones (Eds.), The ethics of sports coaching (pp. 185-198). London: Routledge. 
James, M. (2013). Sports Law. Basingstoke: Palgrave-Macmillan.

Jamieson, L., \& Orr, T. (2009). Sport and Violence: A Critical Examination of Sport. Oxford: Elsevier.

Jones, R. L. (2000). Towards a sociology of coaching. In R. L., Jones \& K. M. Armour (Eds.), Sociology of sport: Theory and practice (pp. 33-43). London: Pearson.

Jones, M., \& Dugdale, A. (Eds.). (2010). Clerk and Lindsell on Torts. London: Sweet and Maxwell/Thomson Reuters.

Kellett, P. (2002). Football-as-War, Coach-as-General: Analogy, Metaphor and Management Implications. Football Studies, 5, 60-76.

Kevan, T. (2005). Sports personal injury. International Sports Law Review, 3, 61-67.

Labuschagne, J., \& Skea, J. (1999). The liability of a coach for a sport participant's injury. Stellenbosch Law Review, 10, 158-183.

Lines, K. (2007). Thinking outside the box(-ing ring): The implications for sports governing bodies following Watson. International Sports Law Review, 4, 64-75.

Lunney, M., \& Oliphant, K. (2013). Tort law: Text and materials. Oxford: Oxford University Press.

Lyle, J. (1999).Lyle, J. (1999). Coaching philosophy and coaching behaviour. In N Cross \& J Lyle (Eds), The Coaching Process: principles and practice for sport (pp. 25-46). Philadelphia: Butterworth-Heinemann.

Lyle, J. (2002). Sports Coaching Concepts: A Framework for Coaches’ Behaviour. London: Routledge.

Lyle, J., \& Cushion, C. (2010). Narrowing the field: Some key questions about sports coaching. In J. Lyle \& C. Cushion (Eds.), Sports coaching: Professionalisation and practice (pp. 361382). Edinburgh: Churchill Livingstone Elsevier.

Lynn, A., \& Lyle, J. (2010). Coaching workforce development. In J. Lyle \& C. Cushion (Eds.), Sports coaching: Professionalisation and practice (pp. 193-207). Edinburgh: Churchill Livingstone Elsevier.

Magnus, U. (2006). Tort law in general. In J. Smits (Ed.), Elgar Encyclopedia of Comparative Law (pp. 719-729). Cheltenham: Edward Elgar. 
Mallett, C. (2010). Becoming a high performing coach: pathways and communities. In J. Lyle \& C. Cushion (Eds.), Sports coaching: professionalisation and practice (pp. 119-134). Edinburgh: Churchill Livingstone Elsevier.

Mangan, D. (2014). The curiosity of professional status. Professional Negligence, 30(2), 74-89.

Martens, R. (2004). Successful Coaching. Leeds: Human Kinetics.

McCaskey, A., \& Biedzynski, K. (1996). A Guide to the Legal Liability of Coaches for a Sports Participant's Injuries. Seton Hall Journal of Sports Law, 6, 7-125.

Miles, A., \& Tong, R. (2013). Sports medicine for coaches. In R. L. Jones \& K. Kingston (Eds.), An introduction to sports coaching: Connecting theory to practice (pp. 177-196). London: Routledge.

Mitten, M. (2013). The Coach and the Safety of Athletes: Ethical and Legal Issues. In R Simon (Ed.), The Ethics of Coaching Sports: Moral, Social, and Legal Issues (pp. 215-233). Boulder, CO: Westview Press.

Montrose, J. (1958). Is negligence an ethical or a sociological concept? The Modern Law Review, 21, 259-264.

Nash, C. (2015). How coaches learn and develop. In C. Nash (Ed.), Practical Sports Coaching (pp. 177-189). Oxon, Routledge.

Nash, C., Sproule, J., \& Horton, P. (2008). Sport Coaches’ Perceived Role Frames and Philosophies. International Journal of Sports Science \& Coaching, 3(4), 539-554.

Norris, W. (2009). The duty of care to prevent personal injury. Journal of Personal Injury Law, 2, 114-134.

Norris, W. (2010). The duty of care owed by instructors in a sporting context. Journal of Personal Injury Law, 4, 183-191.

Partington, M., \& Cushion, C. (2013). An investigation of the practice activities and coaching behaviors of professional top-level youth soccer coaches. Scandinavian Journal of Medicine \& Science in Sports, 23, 374-382.

Partington, N. (2014). Legal liability of coaches: a UK perspective. International Sports Law Journal, 14(3-4), 232-241.

Partington, N. (2015a). What does the Social Action, Responsibility \& Heroism Act 2015 mean 
for sports volunteers and NGBs? LawInSport. Accessed 8 January 82016 $<$ http://www.lawinsport.com/articles/item/what-the-new-social-action-responsibility-heroismact-2015-means-for-sports-volunteers-and-ngbs-references>

Partington, N. (2015b). Professional liability of amateurs: The context of sports coaching. Journal of Personal Injury Law, 4, 232-242.

Partington, N. (2016). 'It’s just not cricket': Or is it? Professional Negligence, 32(1), 77-81.

Pike, E.C.J., \& Scott, A. (2015). Safeguarding injuries and athlete choice. In Lang, M., \& Hartill, M. (Eds.), Safeguarding, Child Protection and Abuse in Sport: International perspectives in research, policy and practice (pp. 172-180). London: Routledge.

Powell, J., \& Stewart, R. (Eds.). (2012). Jackson and Powell on Professional Liability. London: Sweet and Maxwell/Thomson Reuters.

Sports coach UK. (2012). Coach Tracking Study: A four-year study of coaching in the UK. Leeds: Coachwise.

Stirling, A., Kerr, G., \& Cruz, L. (2012). An Evaluation of Canada’s National Coaching Certification Program's Make Ethical Decisions Coach Education Module. International Journal of Coaching Science 6(2), 45-60.

Taylor, B., \& Garratt, D. (2010). The professionalisation of sports coaching: Relations of power, resistance and compliance. Sport, Education and Society, 15(1), 121-139.

Telfer, H. (2010). Coaching practice and practice ethics. In J. Lyle \& C. Cushion (Eds.), Sports coaching: professionalisation and practice (pp. 209-220). Edinburgh: Churchill Livingstone Elsevier.

Trudel, P., Gilbert, W., \& Werthner, P. (2010). Coach education and effectiveness. In J. Lyle \& C. Cushion (Eds.), Sports coaching: Professionalisation and practice (pp. 135-152). Edinburgh: Churchill Livingstone Elsevier.

Vick, D. (2014). Interdisciplinarity and the discipline of law. In D. Cowan, L. Mulcahy, \& S. Wheeler (Eds.), Law and society, (Vol. I, pp. 163-193). London: Routledge.

Whitlam, P. (2012). Safe practice in physical education and sport. Leeds: Association for Physical Education/Coachwise.

Williams, A. M., \& Hodges, N. J. (2005). Practice, instruction and skill acquisition in soccer: Challenging tradition. Journal of sports sciences, 23(6), 637-650. 
Wong, G. (2010). Essentials of Sports Law. Oxford: Praeger.

Young, K. (1993). Violence, risk, and liability in male sports culture. Sociology of Sport Journal 10(4), 373-396.

Young, K. (2004). The Role of the Courts in Sports Injury. In K Young (Ed.) Sporting Bodies, Damaged Selves: Sociological Studies of Sports-Related Injury (pp. 333-353). Oxford: Elsevier.

Young, K. (2012). Sport, Violence and Society. London: Routledge: London.

Young, K., \& White, P. (1999). Threats to Sport Careers: Elite athletes talk about injury and pain. In J. Coakley \& P. Donnelly (Eds), Inside Sports (pp. 203-213). London: Routledge: London.

\section{Cases}

Anderson v Lyotier [2008] EWHC 2790.

Barnett v Chelsea and Kensington Hospital Management Committee [1969] 1 QB 428.

Bolam v Friern Hospital Management Committee [1957] 1 WLR 582.

Bolitho v City of Hackney Health Authority [1998] AC 232.

Bolton v Stone [1951] AC 850.

Brady v Sunderland Association Football Club Limited and Others (Unreported, 2 April, 1998 Queen's Bench Division).

Caldwell v Maguire and Fitzgerald [2001] EWCA Civ 1054.

Caparo v Dickman [1990] 2 AC 605.

Cox v Dundee City Council [2014] CSOH 3.

D v East Berkshire Community Health Authority [2005] 2 AC 373.

Davenport v Farrow [2010] EWHC 550.

Donoghue v Stevenson [1932] AC 562.

Fowles v Bedfordshire County Council [1996] ELR 51.

Morrow v Dungannon and South Tyrone Borough Council [2012] NIQB 50. 
Overseas Tankship (UK) Ltd v The Miller Steamship Co (The Wagon Mound No. 2) [1967] 1 AC 617.

Overseas Tankship v Morts Docks \& Engineering Co Ltd (The Wagon Mound No. 1) [1961] AC 388.

Petrou v Bertoncello and Others [2012] EWHC 2286.

Regina (Daly) v Secretary of State for the Home Department [2001] 2 AC 532.

Uren v Corporate Leisure (UK) Ltd Ministry of Defence [2011] EWCA Civ 66.

Wilsher v Essex Area Health Authority [1987] QB 730.

Woodbridge School v Chittock [2002] EWCA Civ 915.

Woodroffe-Hedley v Cuthbertson, Unreported, 20 June 1997. 